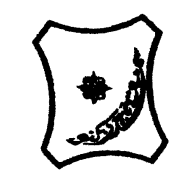

Bayero Journal of Pure and Applied Sciences, 11(1): 195 - 200

ISSN $2006-6996$

\title{
THE INTENSITY OF MALARIA TRANSMISSON AND EFFICACY OF ALPHACYPERMETHRIN AS AN INDOOR RESIDUAL INSECTICIDE AGAINST MALARIA VECTORS IN KADAWA, KANO.
}

\author{
Bashir, B.M., ${ }^{1}$ Abdussalam, Y.M. ${ }^{2}$ and Zainab, T. ${ }^{3}$ \\ ${ }^{1}$ Department of Science Laboratory Technology, School of Technology, Kano State Polytechnic. \\ ${ }^{2}$ Department of Medical Microbiology, Faculty of Clinical Sciences, Bayero University, Kano. \\ ${ }^{3}$ Department of Biological Sciences, Faculty of Life Science, Bayero University, Kano. \\ ${ }^{*}$ Correspondence author:bashirkk85@gmail.com; +2348067676430
}

\section{ABSTRACT}

Malaria is currently affecting more people in the World than any other disease and no single measure of control through the use of drugs seems effective. Malaria is said to kill one African (Whether child or adult every 15 second) and roughly 300,000 Nigerian children annually. A crossectional study was carried out to assess the impact of alphacy phermethrin as an indoor residual insecticide against malaria vectors and transmission in Kadawa irrigation area, Kano. A total of 1897 mosquitoes were collected indoors using WHO standard techniques in the selected areas between December 2010 and June 2011. Specimens were identified using morphological keys and PCR-based assays. ELISA tests were used to detect $P$. falciparum sporozoite infection. Of the 1897 Anopheles mosquitoes collected, An. funestus group, the predominant vector species, represented $63.6 \%$ while An. gambiae s.l. has $18.5 \%$ while other anopheles and culicines $17.9 \%$. The control group (Alpha cyphermethrin treated group) catch 1332 (85.6\%) predominated over the intervention group (Non-alpha cyphernethrin treated group) 224 (14.4\%) with an extreme significant difference $(P<0.0001)$. The result of PCR-based test identified $22 \%$ of the mosquitoes of the Anopheles gambiae complex collected as An. gambiae s.s., $96 \%$ and An. arabiensis as 4\%.The overall sporozoite rates for An. funsetus and An. gambiae s.s. were statistically significant in both groups. Infection rates in both intervention and control group were also statistically significant. The result of the study showed that, the indoor residual spray of alphacyphermethrin has seen to have assisted in reduction of malaria transmission and malaria vectors in the study area from $15.9 \%$ in control group to $4.1 \%$ in intervention group and $78.8 \%$ in control group to $21.2 \%$ in intervention group respectively.

Key words: Malaria; Alpha cyphermethrin; ELISA ; PCR.

\section{INTRODUCTION}

Malaria is a life - threatening parasitic disease transmitted by Anopheles mosquitoes. Malaria remains a major cause of morbidity and mortality in tropical areas despite better knowledge of the pathogenesis and management of severe malaria, the development of resistance to the drugs by the parasites and to the conventional insecticides by the anopheline vectors justifies continues research on the disease (WHO, 2000). The disease affects more than 200 million people in the world over. It is the major problem of the developing countries especially those in the tropical Africa where $90 \%$ of the reported death have been attributed to malaria infection (May et al, 1999, WHO, 2001). More than $40 \%$ of the world population is at risk of the disease (Snow et al, 2005).
It is widespread in tropical and sub-tropical regions, including parts of the Americas (22 countries), Asia, and Africa. Each year, there are more than 250million cases of malaria (Phillips, 2010), killing between one and three million people, the majority who are young children in sub-Saharan Africa (Snow et al., 2005), ninety percent of Malaria related deaths occur in sub-Saharan Africa. Malaria is commonly associated with poverty and can indeed be a cause of poverty (Fong et al., 1971). Malaria is said to kill one African (Whether child or adult every 15 second and roughly 300,000 Nigerian children annually (Salako, 2002). Malaria is naturally transmitted by the bite of a female Anopheles mosquito. Mosquito (from the Spanish or Portuguese word for little fly (Ralph, 2008) is a common insect in the family culicidae (from the Latin culex meaning midge or gnat) (Anonymous, 2009). 
The Anopheles gambiae complex consists of at least seven morphologically indistinguishable species of mosquitoes in the genus Anopheles. The complex was recognised in the 1960s and includes the most important vectors of malaria in sub-Saharan Africa, particularly of the most dangerous malaria parasite, Plasmodium falciparum. It is one of the most efficient malaria vectors known (Walter Reed Army Institute of Research, 2007). Vector control program in the world; mostly rely on the usage of natural and synthetic chemical molecules, which have potential to kill the target insects (WHO, 2003).

Primary malaria prevention on a large scale depends on two vector control interventions: indoor residual spraying (IRS) and insecticide treated mosquito nets (ITNs). Historically, IRS has reduced malaria transmission in many settings in the world, but the health effects of IRS have never been properly quantified. This is important, and will help compare IRS with other vector control intervention. IRS with DDT has been criticized because of supposed environmental damage and physiological resistance of insecticide by the malaria vector. Malathion 25\% WP is used in areas with DDT resistance. The disadvantage of organophosphrous compounds(e.g, malathion) is that unlike their use in agriculture where a farmer uses the organophosphorous compound for crop protection only once or twice a year, the spray squads engaged in spraying residual insecticide in the human dwellings work with these compounds for periods extending up to 6 or 7 months. This long exposure results in acute toxic symptoms and if not control properly may lead to mortality. These compounds are also toxic to domestic pets. Pyrethroids are new insecticides introduced for vector borne diseases. The cost of these insecticides is much higher than the cost DDT and Malathion (Mabaso et al., 2004).

Alpha - cypermethrin is a synthetic pyrethroid insecticide which is man - made chemicals similar in structure to the naturally occurring pyrethrums. Alpha - Cypermethrin kills insects by affecting the salt balance (sodium channels) on nerve cells. It has a broad spectrum of activity against insects with the main toxic effect on the nervous system (Pascual and Peris, 1992).

The study is aimed at assessing the impact of alphacyper-methrin as an indoor residual insecticide against malaria vectors at Kadawa irrigation site, an area of high mosquito density. The present research work reports results of PCR and ELISA studies on Anopheles populations and their relative contribution to malaria transmission in the study area.

\section{MATERIALS AND METHODS \\ Mosquitoes Collection and Morphological Identification}

Adult Anophelines resting and biting indoors were collected monthly using pyrethrum spray collection (Mobil: $3 \%$ tetramethrin, 2\% allethrin, $0.44 \%$ essential oils, and $92.56 \%$ solvents and propellants) (WHO, 2003) from December 2010 to June 2011, in 40 (forty) randomly selected houses. The collection was made between 6:00am to 9:00am on each day of collection. Mosquito's samples were preserved individually in an effendorf tube each and morphologically identified using appropriate keys of Gillies and De mellion (1968) and Gillies and Coetzee (1987).

PCR Identification of Anopheles gambiae Sibling Species

Based on morphological identification, 76 mosquitoes of the Anopheles gambiae s.l. were selected at random from a pool of equal representation of mosquito vectors from the seven months. The DNA used for the PCR identification of the sibling species was extracted from mosquito leg and wings of each of the sample following the procedure of Scott et al, (1993). A thermal cycler (Hybaid, Ashford, U.K.) was used to give initial denaturation at $94^{\circ} \mathrm{C}$ for 2 minutes, followed by 30 cycles of denaturation at $94^{\circ} \mathrm{C}$ for 30 seconds, annealing at $50^{\circ} \mathrm{C}$ for 30 second and extension at $72^{\circ} \mathrm{C}$ for 30 seconds, with a final extension at $72^{\circ} \mathrm{C}$ for 8 minutes. The amplified DNA was separated on a $2.5 \%$-agarose gel, stained with $1 \%$ ethidium bromide and visualized on a ultra-violet transilluminator (Scott et al, 1993).

ELISA Detection of Plasmodium falciparum Circumsporozoite Antigen

Elisa test of Plasmodium falciparum sporozoites were carried out on a total of 136 identified An. gambiae s.s., An. arabiensis and An. funestus group from which samples for the PCR were drawn to quantify and give a precise identification of sporozoite species present. The head and thorax of each of the mosquitoes was crushed in phosphate buffer solution (PBS) of $\mathrm{pH} 7.4$ and tested for circumsporozoite antigen using a double antibody ELISA (Burktot et al, 1984). The results were first recorded visually and then photometrically at $405 \mathrm{~nm}$ using an ELISA plate reader 30 minutes after substrate had been added (Burkot et al, 1984).

\section{RESULTS}

Mosquito Species Composition

A total of 1897 adult mosquitoes were collected from both intervention (Alpa cyphermethrin treated group) and control (Non-alpha cyphermehtrin treated group) groups within a period of seven month and 1206 (63.6\%) 
of these were identified as Anopheles funestus, $350(18.5 \%)$ as Anopheles gambiae s.l. while $247(12.9 \%)$ as other species of Anopheline mosquitoes. The remaining 94 (5.0\%) mosquitoes were culicines. The overall number of Anopheles funestus caught was significantly higher ( $P$ value is 0.0001$)$ than the number of Anopheles gambiae collected. The control group catch 1332 (85.6\%) predominated over the intervention group $224(14.4 \%)$ with an extreme significant difference $(P$ value is 0.0001)

Table 1: Relative abundance of the Anopheline mosquitoes within Anopheles gambiae complex and Anopheles funestus group in control and intervention communities.

\begin{tabular}{llllll}
\hline & $\begin{array}{l}\text { Intervention } \\
\text { group }\end{array}$ & $\begin{array}{l}\text { Percentage } \\
(\%)\end{array}$ & $\begin{array}{l}\text { Control } \\
\text { group }\end{array}$ & $\begin{array}{l}\text { Percentage } \\
(\%)\end{array}$ & $\begin{array}{l}\text { Total } \\
(\%)\end{array}$ \\
\hline $\begin{array}{l}\text { An. } \\
\text { gambiae }\end{array}$ & 180 & 51.4 & 170 & 48.6 & $\begin{array}{l}350 \\
(22.5)\end{array}$ \\
$\begin{array}{l}\text { An. } \\
\text { funestus }\end{array}$ & 44 & 3.6 & 1162 & 96.4 & $\begin{array}{l}1206 \\
\text { Total }\end{array}$ \\
\hline
\end{tabular}

Seasonal variation in the relative abundance of mosquitoes in the study communities

The number of the mosquitoes species identified in the sampled communities varied according to the season of the year (Table 2). The overall number of mosquitoes collected in the wet season $1364 \quad(71.9 \%)$ was not significantly different when compared statistically with that of dry season $533(28.1 \%)$ ( $P$ value is 0.5742 ).

Molecular characterization of sibling's species within Anopheles gambiae complex

Polymerase chain reaction assays: The Anopheles gambiae species specific PCR assay was employed to distinguish the cryptic species present within the Anopheles gambiae group. Out of the 350 identified as Anopheles gambiae s.l. a total of 76 were randomly selected representing all the seven months and study areas. Of the total Anopheles gambiae analyse, 72 (96\%) were identified as Anopheles gambiae s.s. while 3 (4\%) were Anopheles arabiensis (Table 3). The results obtained shows no significant statistical difference between the populations of Anopheles gambiae s.s. and Anopheles arabiensis ( $\mathrm{P}>0.1151)$. However, $2.6 \%$ of the species could not be identified.

Table 2: Seasonal variation in the relative abundance of mosquitoes in the study communities

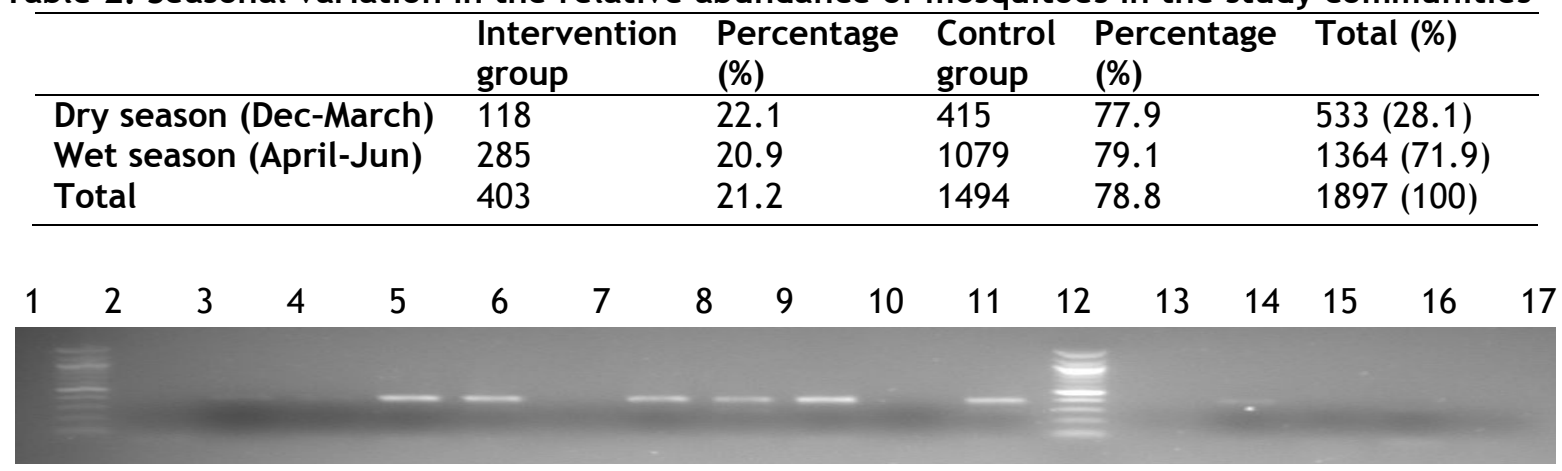

Figure 1: PCR identification of one sibling species within Anopheles gambiae Using Lane 1 and 17 as markers

Lane 1 is a Kb DNA ladder (standard); Lane 2, 7 and 11 shows no amplication; Lane 3-6, 8-10, 12-14 are An. gambiae s.S.; Lane 15 is a positive control of An. gambiae s.s.; Lane 16 is a Negative control and Lane 17 is a Positive control of An. arabiensis (Nigerian Institute of Medical Research Yaba, Lagos, 2011)

$$
\begin{array}{llllllllllllllllllll}
1 & 2 & 3 & 4 & 5 & 6 & 7 & 8 & 9 & 10 & 11 & 12 & 13 & 14 & 15 & 16 & 17 & 18 & 19 & 20
\end{array}
$$

Figure 2: PCR identification of one Sibling's species within Anopheles gambiae Using Lane 1 and 20 as markers

Lane 1 is a Kb DNA ladder (standard) while Lane 2-20 is an An. gambiae s.s. (Nigerian Institute of Medical Research Yaba, Lagos, 2011). 
Table 3: Sibling species composition of female Anopheles gambiae complex identified in the study area.

\begin{tabular}{llllll}
\hline Species & $\begin{array}{l}\text { Numbers } \\
\text { identified }\end{array}$ & $\begin{array}{l}\text { Percentage } \\
(\%)\end{array}$ & $\begin{array}{l}\text { Intervention } \\
\text { group (\%) }\end{array}$ & $\begin{array}{l}\text { Control } \\
\text { group } \\
(\%)\end{array}$ & Total (\%) \\
\hline An. Gambiae & 72 & 96 & $38(50.7)$ & 34 & $72(96)$ \\
& 3 & 4 & $0(0.0)$ & $3(100)$ & $3(4)$ \\
An arabiensis & 75 & 100 & 38 & 37 & $75(100)$ \\
\hline Total & & & &
\end{tabular}

Table 4: Number of mosquitoes tested and percentage found carrying Plasmodium falciparum circumsporozoite antigens in both intervention and control groups

\begin{tabular}{lllllll}
\hline & \multicolumn{2}{l}{$\begin{array}{l}\text { Intervention } \\
\text { Group }\end{array}$} & \multicolumn{2}{l}{ Control Group } & Total \\
& $\begin{array}{l}\text { No. } \\
\text { tested }\end{array}$ & $\begin{array}{l}\text { No. } \\
\text { positive } \\
(\%)\end{array}$ & $\begin{array}{l}\text { No. } \\
\text { tested }\end{array}$ & $\begin{array}{l}\text { No. } \\
\text { positive } \\
(\%)\end{array}$ & $\begin{array}{l}\text { No. } \\
\text { tested }\end{array}$ & $\begin{array}{l}\text { No. } \\
\text { positive } \\
(\%)\end{array}$ \\
\hline An. gambiae & 66 & $2(3.0)$ & 45 & $7(15.6)$ & 111 & $9(8.1)$ \\
An arabiensis & 0 & $4(0)$ & 3 & $0(0.0)$ & 3 & $0(0.0)$ \\
An. funestus group & 7 & $1(14.3)$ & 15 & $3(20.0)$ & 22 & $4(18.2)$ \\
Total & 73 & $3(4.1)$ & 63 & $10(15.9)$ & 136 & $13(9.6)$ \\
\hline
\end{tabular}

Plasmodium falciparum sporozoite rates

Out of the 1803 Anopheles mosquitoes collected, 136 were processed for $P$. falciparum circumsporozoite protein ELISA antigen test. The selection was based on the having representativeness of the caught mosquitoes from different areas in the study area and different months. Thirteen $(9.6 \%)$ of the 136 Anopheles mosquitoes tested for Plasmodim falciparum circumsporozoite antigen (CSA) were positive. The sporozoite rate was $8.1 \%$ for Anopheles gambiae s.S., $18.2 \%$ for Anopheles funestus group and $0 \%$ for Anopheles arabiensis (Table 4). The Overall sporozoite rates Anopheles gambiae s.s. and Anopheles funestus group were statistically significant in both the study groups ( $P$ value is 0.0203 ). The percentage of mosquitoes found to be carrying Plasmodium falciparum circumsporozoite antigen fell or decline from $15.9 \%$ in the control group to $4.1 \%$ in the intervention group. The intervention group rates were however significantly lower than the control group rates ( $P$ value is 0.0203 ).

\section{DISCUSSION}

In the present study a total of 1817 indoor resting knock down mosquito were collected from both control and intervention group throughout the study period. $403(21.2 \%)$ of the total mosquitoes collected were from intervention group and 1494 (78.8\%) were from control group (Table 2). This shows that the indoor residual spray of alpha cyphermethrin in the study area play insignificant role in reducing vector densities, when the total number of mosquitoes collected from intervention group were compared statistically with that of control group by Fishers exact test the result shows no significant different ( $p$ value is 0.5742 ). The results of the present study do not correlate with the findings of Lein et al, (2008) and Rowland et al, (2000) which shows that Alpha cypermethrin appears highly suited for the control of malaria in Pakistan, Democratic Republic of Sao Tome and Principe and South Asia. It is highly toxic to vectors, requires only one treatment per year, and was appreciated by the community.

The result for vector density in intervention group shows that out of $403(21.2 \%)$ of mosquitoes collected $362(19.8 \%)$ of the collected mosquito were Anopheles as against $1441(76 \%)$ out of $1494(78.8 \%)$ of the collected mosquito from control group which indicates a high density and risk of becoming infected with malaria.

Out of 1803 Anopheles mosquitoes collected $1556(86.3 \%)$ fall into 2 major groups of Anopheles mosquito: Anopheles gambiae (22.5\%) and Anopheles funestus(77.5\%) (Table1). This result is in concordance with many reports from different part of the world. Oyewole et al, (2005) shows that Anopheles gambiae and Anopheles funestus group constituted the largest proportion of malaria vector in Nigeria.

Large number of Anopheles funestus collected in the control group could be due to the location of the village and its proximity to the slow moving irrigation channel. (Table 1). 
The seasonal variation in mosquito abundance indicates its dependence on the rain. Seasonal variations in population, distribution and composition of Anopheline mosquitoes were observed in all the study communities. The wet season collection was almost three times higher than that of the dry season.

The PCR identification study results confirmed that Anopheles gambiae s.s. constituting $96 \%$ $(n=77)$ is the predominant vector of malaria in the study area. This is in concordance with Oyewole et al, (2005) who reported that Anopheles gambiae s.s. and Anopheles arabiensis occur in sympatric and in the same vicinity.

The present study showed that sporozoite rates in Anopheles gambiae s.s and Anopheles funestus were statistically significant $(P$ value is 0.203) (Table 4), this is not in line with the findings of Haridi, (1972); Ameneshewa et al, (1996) and Fettene et al., (2004) which show that sporozoite rates in Anopheles gambiae s.s, Anopheles arabiensis and Anopheles funestus were statistically insignificant. The finding of natural sporozoite rates in the salivary gland of Anopheles gambiae s.s (8.1\%) and Anopheles funestus $(18.2 \%)$ all of which were caught indoors by pyrethrum spray collection emphasizes their epidemiological importance in malaria transmission in the study area.

\section{REFERENCES}

Anonymous, (2009). Mosquito. Available at: http://en.wikipedia.org/wiki/Mosquito.

Ameneshewa, B., and Service, M.W. (1996). Resting habits of Anopheles arabiensis in the Awash River valley of Ethiopia. Annals of tropical medicine and parasitology 90: 515-521.

Burkot, T.R., Williams, J.L. and Schneider, I. (1984). Identification of plasmodium falciparum - infected mosquitoes by a double antibody enzyme - linked immunosorbent assay. American Journal of Tropical Medicine and Hygiene 33: 783 - 788.

Fettene, M., Hunt, R. H., Coetzee, M. and Tennessee, F. (2004). Behaviour of Anopheles arabiensis and An. quadriannulatus species. B mosquitoes and malaria transmission in southwestern Ethiopia. African entomology. 12 (1):83-87.

Fong Y.L., Cadigan F.C., and Coatney G.R. (1971). "A presumptive case of naturally occurring Plasmodium knowlesi malaria in man in Malaysia". Transactions of the Royal Society of Tropical Medicine and Hygiene 65 (6): 839-40.
The $0 \%$ sporozoite rate recorded for Anopheles arabiensis showed that it plays no tangible role in malaria transmission in the study area. Lower sporozoite rates observed in intervention group (4.1\%) indicates low intensity of malaria transmission in the area (Table 4).

\section{CONCLUSION}

Based on the finding of the present study, it could be deduced that:

The finding of natural sporozoite rates in the salivary gland of Anopheles gambiae s.s (8.1\%) and Anopheles funestus (18.2\%) all of which were caught indoors by pyrethrum spray collection emphasizes their epidemiological importance in malaria transmission in the study area.

Although no much reduction in malaria parasite vector density was recorded in the study area, the indoor residual spray of alpha cyphermethrin was seen to have assisted in reduction of malaria transmission and malaria vectors in the study area from $15.9 \%$ in control group to $4.1 \%$ in intervention group and $78.8 \%$ in control group to $21.2 \%$ in intervention group respectively.

Members of Anopheles funestus group are the major malaria vectors in Kadawa irrigation area of Kano state, Nigeria.

Gillies M.T., and De Meillon B. (1968). The Anophelinae of Africa south of the Sahara (Ethiopian Zoogeographical Region) Publication of South Africa Institute of Medical Research 1968; 54: 343.

Gillies, M.T and Coetzee, M. (1987). A supplement to the Anophelinae of Africa South of the Sahara (Afrotropical Region).

Haridi, A. M. (1972). Partial exophily of Anopheles gambiae species B in the Khasem Elgirba area in eastern Sudan. Bulletin of the World Health Organisation. 46: 39-46.

Lien F. T., Wen C. C., Malaria C. F., Cheng H. W., Heroides S. R., and Jih C. L. (2008). Rapid Control of Malaria by means of indoor Residual Spraying of Alphacyphermethrin in the Democratic Republic of Sao Tome and Principe. American Journal of Tropical Medicine and Hygiene 78: 248-250.

Mabaso ML, Sharp B, Lengeler C (2004). "Historical review of malarial control in southern African with emphasis on the use of indoor residual housespraying". Trop. Med. Int. Health. 9 (8): 846-56. 
May, J., Mockenhaupt, F.P., Ademowo, O.G., Olumese, P.E., bienzele, $U$ and Meyer, C.G. (1999). High rate of mixed and sub patient malarial infections in Southwestern Nigeria. American journal of Tropical Medicine and Hygiene, 61, 339-343.

Nigerian institute of medical research yaba, Lagos (2011). A polymerase chain reaction gel picture.

Oyewole I.O., Ibidapo C.A., Oduola A.O., Awolola T.S. and Obansa J.A. (2005). Molecular identification and population dynamics of the major malaria vectors in a rain forest zone of Niger Biokemistri ; 17(2): 171-8.

Pascual, J.A.; S.J. Peris (1992). "Effects of forest spraying with two application rates of cypermethrin on food supply and on breeding success of the blue tit (Parus caeruleus)". Environmental Toxicology and Chemistry. 11 (9): 1271-1280.

Phillips, N. (2010). "Gorillas in midst of malaria mystery". Sydney Morning Hearld. http://www.smh.com.au/environment/ conservation/gorillas-in-midst-ofmalaria-mystery-20100925-15rlm.html.

Rowland, M., Mahmoud, P., Igbal, J., Carneiro, I. and Chavasse, D. (2000). Indoor residual spraying with alphacypermethrin controls malaria in
Pakistan: a community - randomized trial. Tropical Medicine and International Health 5: 472 - 481.

Salako, L.A. (2002). National malaria day malaria awareness walks. Text of an address given on the occasion on the malaria awareness work held in Abuja .Journal of malaria of Africa and Tropics, 1:6-7.

Scott J.A., Brogdon W.G., and Collins F.H. (1993). Identification of single specimens of the Anopheles gambiae complex by polymer-ase chain reaction. American Journal of Tropical Medicine and Hygiene 1993 49: 520-9.

Snow R.W., Guerra C.A., Noor A.M., Myint H.Y. and Hay S.I. (2005). "The global distribution of clinical episodes of Plasmodium falciparum malaria". Nature 434 (7030): 214-7.

Walter Reed Army Institute of Research. (2007) "Anopheles gambiae complex". Archived from the original on 2007-09-29.

World Health Organization, (2000), and complicated malaria. Transaction of the Royal Society of Tropical Medicine and Hygiene 84 (2) 1065.

World Health Organization (2001). What is Malaria? RBM info sheet. Geneva.

World Health Organization, (2003). Malaria entomology and vector control page 25. 